\title{
The Virtual Enterprise Member's Three-Tier Selection Model Based on Credit and Reward Distribution
}

\author{
Y. Chen, Y. Jing \\ Department of Mathematics and Information Science \\ Guiyang University \\ Guizhou, China
}

\begin{abstract}
In order to optimize the virtual enterprise members' selecting process, the selection strategy thinks about not only the potential partner's ability, but also the potential partner's credibility. Firstly, this paper designed the potential partner's reputation algorithm to complete initial screening, then designed the potential partner's credit algorithm to complete secondary screening, after confirming the members' credibility, designed the reward distribution strategy, selected the members of the virtual enterprise. By the results of Multi-agent simulation, verify that the Three-tier selection model is reliable and effective.
\end{abstract}

Keywords-virtual enterprise member selection; three-tier selection model; multi-agent simulation

\section{INTRODUCTION}

The Virtual Enterprise (VE) is built on the basis of the information network and share information, technology and cost among the members, so, it is joint development and mutually beneficial business alliances [1]. A virtual enterprise (VE) life cycle include formation, running, dissolution etc[2]. Cooperation is the most important content in a virtual enterprise (VE). In order to provide a good premise for the cooperation, selecting partners is crucial.

Most member's selection strategies were focus on the potential partners' core competencies and strength, that can directly reflect whether they completed the task of VE successfully. But virtual enterprise (VE) is an alliance, mutual trust and cooperation is the most important. In selecting members' phases, thinking about not only the potential partners' competitive strength, but also the potential partners' credibility, that the selection strategy would be more reasonable and reliable. The selection strategy named three-tier selection model is designed in Figure 1:

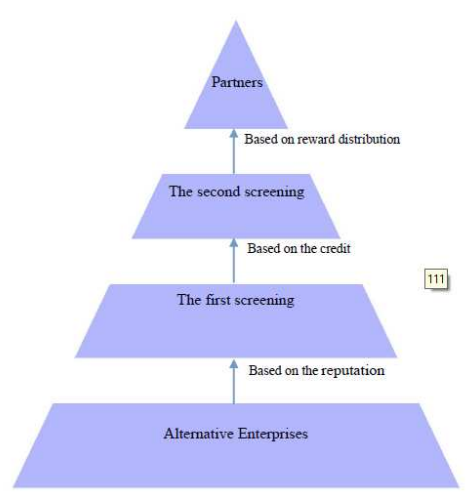

FIGURE I. THE STRUCTURE OF THREE-TIER SELECTION MODEL
The figure shows that selecting the members can be divided into three steps. Firstly, according to the third-party evaluation, design the reputation algorithm, get each potential partner's reputation and complete the first screening. Secondly, according to the cooperation experience between the core enterprise and the potential partners, design the credit algorithm, get each potential partner's credit and complete the second screening. Finally, design the reward distribution algorithm, select the members to form the virtual enterprise.

\section{THREE-TIER SELECTION MODEL}

According to the structure design, sequentially design the reputation algorithm, the credit algorithms and the reward allocation algorithm, and then create the three-tier selection model.

\section{A. Design the Reputation Algorithm}

Reputation is a kind of evaluation come from the third parties [3]. According to knowing about each potential partner's reputation, the core enterprise can select some potential partners that have a good reputation.

$\mathrm{TP}_{\mathrm{i}}$ stands for one of the third parties, $A=\left\{\mathrm{a}_{1}, \mathrm{a}_{2} \cdots \cdots \mathrm{a}_{\mathrm{n}}\right\}$ stands for the potential partner set, $E=\left\{e_{1}, e_{2}, \cdots \cdots e_{n}\right\}$ stands for evaluation of a third party to make $n$ aspects, $\operatorname{Re}_{\mathrm{TP}_{\mathrm{i}} \rightarrow \mathrm{a}_{\mathrm{i}}}$ represents the reputation of $\mathrm{TP}_{\mathrm{i}}$ to $\mathrm{a}_{\mathrm{i}}$ :

$$
\operatorname{Re}_{\mathrm{TP}_{\mathrm{i}} \rightarrow \mathrm{a}_{\mathrm{i}}}=\sum_{1}^{\mathrm{n}} \mathrm{e}_{\mathrm{i}} \bullet \mathrm{f}_{\mathrm{w}}\left(\mathrm{i}, \mathrm{e}_{1: \mathrm{n}}\right)
$$

In eqn (1), $e_{i} \in[0,1], f_{w}\left(i, e_{1: n}\right)$ is the weighting function of the evaluation of a third party:

$$
\mathrm{f}_{\mathrm{w}}\left(\mathrm{i}, \mathrm{e}_{1: \mathrm{n}}\right)=\frac{\mathrm{e}_{\mathrm{i}}}{\sum_{\mathrm{j} \in \phi} \mathrm{e}_{\mathrm{j}}}\left(\varphi=\left\{\mathrm{j} \mid \mathrm{e}_{\mathrm{j}}>\alpha\right\}\right)
$$

In eqn (2), $\alpha$ is a threshold, if $e_{j}$ is less than $\alpha, \mathrm{f}_{\mathrm{w}}\left(\mathrm{i}, \mathrm{e}_{1: \mathrm{n}}\right)$ is 0 .

If $\operatorname{Re}_{\mathrm{TP}_{\mathrm{i}} \rightarrow \mathrm{a}_{\mathrm{i}}}$ is 1 , the reputation is best. If $\operatorname{Re}_{\mathrm{TP}_{\mathrm{i}} \rightarrow \mathrm{a}_{\mathrm{i}}}$ is 0 , the reputation is worst.

\section{B. Design the Credit Algorithm}

Trust is a kind of conviction about the potential partners' reliability, honesty and core competence [4]. According to the reputation algorithm, the core enterprise can get each potential 
partner's reputation. However, there may be the unfair and negative evaluation from a third party, so, only the reputation is not enough to measure an potential partner's credibility. The core enterprise should also think about the cooperation experience with the potential partner.

1 stands for the core enterprise, $\operatorname{Re}=\left\{r_{1}, r_{2}, \cdots \cdots r_{n}\right\}$ stands for the potential partners' reputation set, $C o=\left\{c_{1}, c_{2}, \cdots \cdots c_{n}\right\}$ stands for the cooperation experience between the core enterprise and the potential partners, $\mathrm{f}_{\mathrm{e}(}(\mathrm{l}, \mathrm{c})=\left[\mathrm{f}_{\mathrm{e} 1(}\left(\mathrm{l}, \mathrm{c}_{1}\right), \mathrm{f}_{\mathrm{e} 2}(\mathrm{l}\right.$, $\left.\left.c_{2}\right), \cdots \cdots f_{e(}\left(l, c_{n}\right)\right]$ stands for the assessment that the core enterprise assess each cooperation experience, $\mathrm{f}_{\mathrm{e}(}(\mathrm{l}, \mathrm{c}) \in[-1,1]$. $\mathrm{CR}_{\mathrm{k}}\left(\mathrm{c}_{\mathrm{i}}\right)$ represents the ith potential partner' $\mathrm{s}$ credit:

$$
\mathrm{CRk}(\mathrm{ci})=\xi \bullet \mathrm{CE}_{1 \rightarrow \mathrm{c}_{\mathrm{i}}}+(1-\xi) \bullet \operatorname{Re}
$$

In eqn (3), $\xi \in[0,1], \xi$ stands for the reliability of cooperation experience. $\mathrm{CE}_{1 \rightarrow c_{\mathrm{i}}}$ stands for the value of the cooperation experience of 1 to $\mathrm{A}$ :

$$
\mathrm{CE}_{1 \rightarrow \mathrm{c}_{\mathrm{i}}}=\sum_{\mathrm{i}=1}^{\mathrm{n}} \mathrm{c}_{\mathrm{i}} \bullet \mathrm{f}_{\mathrm{e}_{\mathrm{i}}}\left(\mathrm{l}, \mathrm{c}_{\mathrm{i}}\right)
$$

We can select the more reliable and credible potential partners by the two algorithms.

\section{Design the Reward Distribution Algorithm}

According to the previous algorithms, the credible potential partners have been selected, and then should think about their business ability. According to gambling machines arm theory, the more powerful arm can get more rewards. Assume the rewards have three types: cost, time limit for one project and core competence (for specific business), the description is in Table 1:

\section{TABLE I. THE PROPERTY OF REWARD}

\begin{tabular}{ll}
\hline Project & description \\
\hline $\mathbf{T}_{\mathrm{ij}}$ & $\begin{array}{l}\text { ith potential partner provide the technology costs to } \\
\text { complete jth business } \\
\mathbf{E}_{\mathrm{ij}}\end{array}$ \\
$\begin{array}{l}\text { ith potential partner provide the experience cost to } \\
\text { complete jth business } \\
\mathbf{F}_{\mathrm{ij}}\end{array}$ & $\begin{array}{l}\text { ith potential partner provide the financial cost to } \\
\text { complete } \mathrm{jth} \text { business }\end{array}$ \\
\hline Cost $_{\mathrm{ij}}$ stands for the cost of completing the task: \\
\end{tabular}

Time $_{i j}$ stands for the period of completing the task, a stands for the size of the task:

$$
\text { Time }_{\mathrm{ij}}=\alpha / \mathrm{T}_{\mathrm{ij}}
$$

Core $_{\mathrm{ij}}$ stands for the core competencies of completing the task:

$$
\operatorname{Core}_{\mathrm{ij}}=\beta * E_{i j}\left(1-\exp ^{-x F_{i j}}\right)
$$

In eqn (7), $\beta$ stands for the matching experience values, $x$ stands for the financial situation values.

According to the task and the potential partners providing the rewards, design three reward distribution algorithms:

- The minimum cost algorithm
Select the partners that provide the minimum cost to complete the task.

$$
\mathrm{C}_{\mathrm{sj}}=\operatorname{Min}\left(\operatorname{Cost}_{1 \mathrm{j}}, \operatorname{Cost} 2 \mathrm{j} \ldots \ldots \operatorname{Cost}_{\mathrm{nj}}\right)
$$

- The minimum time limit algorithm

Select the partners that provide the minimum time limit to complete the task.

Time $_{\mathrm{sj}}=$ Min $\left(\right.$ Time $_{1 \mathrm{j}}, \mathrm{Time}_{2 \mathrm{j}} \ldots .$. Time $\left._{\mathrm{ij}}\right)$

- The optimal core competencies algorithm

Select the partners that provide the optimal core competencies to complete the task.

Core $_{\mathrm{ij}}=\operatorname{Max}\left(\right.$ Core $_{1 \mathrm{j}}$, Core $_{2 \mathrm{j}} \ldots \ldots$ Core $\left._{\mathrm{nj}}\right)$

- The comprehensive evaluation algorithm Firstly, calculate the cost:

$$
\mathrm{C}_{\mathrm{ij}}=\frac{\left(\operatorname{Cost}_{\mathrm{ij}}-\overline{\mathrm{C}_{\mathrm{j}}}\right)}{\mathrm{SD}_{\mathrm{c}_{\mathrm{J}}}}
$$

In the eqn(11), $\overline{\mathrm{C}_{\mathrm{j}}}$ stands for the average cost that all the potential partners to complete jth task. $\mathrm{SD}_{\mathrm{c}_{\mathrm{J}}}$ stands for the cost standard deviation.

Secondly, calculate the time limit value:

$$
\mathrm{T}_{\mathrm{ij}}=\frac{\left(\text { Time }_{\mathrm{ij}}-\overline{\mathrm{T}_{\mathrm{j}}}\right)}{\mathrm{SD}_{\mathrm{T}_{\mathrm{j}}}}
$$

In the eqn (12), $\frac{T_{j}}{T_{j}}$ stands for the average time limit that all potential partners to complete jth task. $\mathrm{SD}_{\mathrm{T}_{\mathrm{J}}}$ stands for the time limit standard deviation.

Next, calculate the core competencies:

$$
\mathrm{CO}_{\mathrm{ij}}=\frac{\left(\mathrm{Core}_{\mathrm{ij}}-\overline{\mathrm{CO}_{\mathrm{j}}}\right)}{\mathrm{SD}_{\mathrm{CO}_{\mathrm{J}}}}
$$

In the eqn (13), $\overline{\mathrm{CO}_{\mathrm{j}}}$ stands for the average core competencies that all the potential partners to complete jth task. $\mathrm{SD}_{\mathrm{CO}_{\mathrm{J}}}$ stands for the core competencies standard deviation.

So, the comprehensive evaluation algorithm can be described:

$\left(\mathrm{C}_{\mathrm{ij}}, \mathrm{T}_{\mathrm{ij}}, \mathrm{CO}_{\mathrm{ij}}\right)=\operatorname{Max}\left\{\left(\mathrm{C}_{\mathrm{ij}}, \mathrm{T}_{\mathrm{ij}}, \mathrm{CO}_{\mathrm{ij}}\right),\left(\mathrm{C}_{2 \mathrm{j}}, \mathrm{T}_{2 \mathrm{j}}, \mathrm{CO}_{2 \mathrm{j}}\right) \ldots\left(\mathrm{C}_{\mathrm{nj}}, \mathrm{T}_{\mathrm{nj}}, \mathrm{CO}_{\mathrm{nj}}\right)\right\}$

According to the eqn (14), select the partner that owns the optimal comprehensive evaluation to be a member of the VE.

In summary, according to the three designed algorithms, design the three-tier selection model layer by layer.

\section{THE SIMULATION AND ANALYSIS}

In order to verify the effectiveness of the three-tier selection model, simulate on the RePast.

Firstly, simulate the reputation algorithm and the credit algorithm. $\mu$ stands for the true value that each agent complete a task. In the $[0.2,0.4,0.6,0.8,1.0], \mu$ is generated randomly 
and equal probability. Assume $a$ is 0.5 , the Figure 2 shows the simulation result:
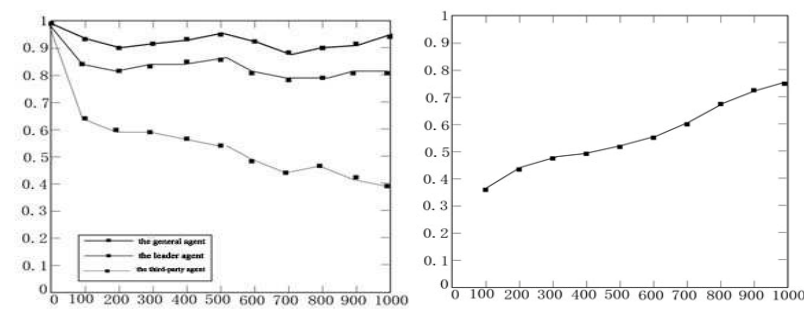

FIGURE II. THE AVERAGE CREDIT CHANGES AND SATISFACTION

Next, simulate the reward distribution algorithm. The active area is a $500 * 500$ square region, time unit is week and simulation time is for 200 weeks. The simulation state is in Figure 3:

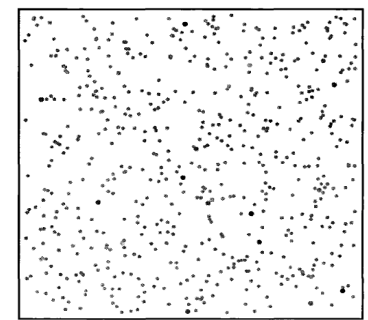

FIGURE III. THE SIMULATION STATE 2.

The four reward distribution algorithms results are in Table

TABLE II. THE FOUR REWARD DISTRIBUTION ALGORITHM RESULTS

\begin{tabular}{|c|c|c|c|c|c|c|c|c|}
\hline \multirow{2}{*}{ items } & \multicolumn{2}{|c|}{$\begin{array}{c}\text { The minimum } \\
\text { cost }\end{array}$} & \multicolumn{2}{|c|}{$\begin{array}{c}\text { The minimum } \\
\text { time limit }\end{array}$} & \multicolumn{2}{|c|}{$\begin{array}{c}\text { The optimal } \\
\text { core } \\
\text { competencies }\end{array}$} & \multicolumn{2}{|c|}{$\begin{array}{c}\text { The } \\
\text { comprehensiv } \\
\text { e evaluation }\end{array}$} \\
\cline { 2 - 9 } & mean & $\begin{array}{c}\text { standard } \\
\text { deviatio } \\
\mathrm{n}\end{array}$ & mean & $\begin{array}{c}\text { standar } \\
\mathrm{d} \\
\text { deviatio } \\
\mathrm{n}\end{array}$ & mean & $\begin{array}{c}\text { standard } \\
\text { deviatio } \\
\mathrm{n}\end{array}$ & mean & $\begin{array}{c}\text { standard } \\
\text { deviatio } \\
\mathrm{n}\end{array}$ \\
\hline The Cost & 121.2 & 2.51 & 211.3 & 3.24 & 221.1 & 6.81 & 236.1 & 2.41 \\
\hline $\begin{array}{c}\text { The time } \\
\text { limit }\end{array}$ & 45.16 & 1.86 & 21.54 & 0.31 & 37.53 & 4.93 & 22.71 & 0.31 \\
\hline $\begin{array}{c}\text { The core } \\
\text { competen } \\
\text { ce }\end{array}$ & 43.65 & 3.01 & 91.21 & 5.17 & 151.2 & 1.68 & 139.6 & 2.89 \\
\hline
\end{tabular}

According to the simulation results, the three-tier selection model runs stably and has validity and controllable.

\section{CONCLUSIONS}

Based on the analysis of the current virtual enterprise (VE) selecting members algorithm and their problems, this paper suggests selecting members strategy should think about the potential partners' credit first, and then designs the three-tier selection model. According to the simulation results, the threetier selection model runs stably and it has validity and controllable.

Although the three-tier selection model has a lot of improvements, but there are still some inadequacies. For example, how to avoid the third-party's unfair evaluation, the weights are not defined clearly, and the core competencies is difficult to calculate.

\section{ACKNOWLEDGMENTS}

This work was financially supported by the Guizhou Science and Technology Office Joint Foundation (LKG[2013]43).

\section{REFERENCES}

[1] F. Tao,K. Qiao, L. Zhang, Z. Li, A.Y.C. Nee.,GA-BHTR: an improved genetic algorithm for partner selection in virtual manufacturing. International Journal of Production Research, (8),pp. 121-126, 2012.

[2] Qiang Zhao,Xinhui Zhang,Renbin Xiao. ,Particle swarm optimization algorithm for partner selection in virtual enterprise. Progress in Natural Science, (11),pp 78-82, 2008.

[3] Fei Ye,Yi-Na Li.,Group multi-attribute decision model to partner selection in the formation of virtual enterprise under incomplete information. Expert Systems With Applications, (5),pp.107-113, 2009.

[4] CNNIC, www.cnnic.cn 